Original scientific paper

\title{
OPTIMIZATION OF FLEXIBLE PRODUCTION LOGISTICS UNDER LOW CARBON CONSTRAINT
}

\author{
Wang, Z. J.* \& Suo, J.**\# \\ * Business School, Inner Mongolia University of Finance and Economics, Hohhot 010000, China \\ ${ }^{* *}$ School of Economics and Management, Inner Mongolia University of Technology, Hohhot 010000 , \\ China \\ E-Mail: jingsuo@imut.edu.cn (" Corresponding author)
}

\begin{abstract}
Flexible production centring on machines or job-shops is necessary to meet the current trend of production and sales. By studying the energy consumption of production logistics, it is possible to minimize energy consumption and carbon emissions of the production process, without sacrificing production efficiency. The existing studies all try to optimize the logistics distribution. None of them attempt to optimize both production and logistics distribution parameters, and low carbon emission indices. Therefore, this paper explores the multi-objective optimization and carbon efficiency evaluation of flexible production logistics under low carbon constraint. Specifically, the constraint order between production logistics time, logistics quality, logistics cost, and low-carbon degree was determined, and the expressions of four linear programming models were given. Moreover, the carbon efficiency optimization of flexible production logistics was redefined, and a mathematical model was developed for the carbon efficiency optimization problem, which simultaneously optimizes carbon emissions and production indices. The proposed model was proved scientific through experiments.

(Received in November 2021, accepted in February 2022. This paper was with the authors 2 weeks for 1 revision.)
\end{abstract}

Key Words: Carbon Efficiency, Flexible Production Logistics, Low Carbon Constraint, Linear Programming

\section{INTRODUCTION}

The defining trend of production and sales is the delivery of various products in multiple small batches within a short cycle. To meet to this trend, it is necessary to carry out flexible production centring on machines or job shops [1-6]. Flexible logistics provides a new logistics model that adapts to the personalized demand for production, sales, and consumption in the society today. It requires the logistics distribution centres of goods or parts to design and implement flexible logistics operations, according to the features of actual production, sales, and consumption [7-14]. By studying the energy consumption of production logistics, it is possible to optimize the flexible logistics carbon efficiency, thereby minimizing energy consumption and carbon emissions of the production process, without sacrificing production efficiency [15-20]. The results of the relevant studies provide a realistic guide for China's manufacturing industry to reduce the consumption of production resources and energy, lower carbon emissions, and eventually realize green production.

During logistics distribution, the transportation system is often interfered with complex factors. Lin and Chan [21] studied the path optimization problem of logistics enterprises in a time-varying transportation environment. Firstly, the dynamicity of vehicle speed was processed, and the path optimization method was proposed for consumers. Next, a green distribution path optimization model was established considering the time window of consumer services, aiming to minimize carbon emissions and total travel time. Taking carbon cap as a key indicator of optimal logistics scale, Ying [22] evaluated the relevant green investment costs and transportation prices, and determined the correlations between transportation service costs of different scales and the predicted transportation prices. To effectively promote energy saving and sustainable development of the entire industry and logistics systems, reduce enterprise cost, 
and optimize overall resources, Islam et al. [23] constructed a mode based on low-carbon logistics and green supply chain, realized low-carbon logistics management, developed an esupply chain-based logistics management system, and proposed improvement measures for the system. For the sustainable development of transportation industry, De et al. [24] introduced the green cluster logistics problem under carbon cap based on vehicle fleet, and treated the carbon emissions of vehicles as a function of travel distance, speed, and cargo load. Considering the incomplete economic production lot size (EPL) model with a time-invariant defect rate, Nouira et al. [25] held that the carbon cap of the local government hinders production and sales, provided a profit maximization algorithm for enterprise managers, and illustrated the algorithm with examples.

Many scholars have explored flexible production logistics. But few have integrated lowcarbon factors into flexible production logistics and multi-objective optimization system [26]. Concerning the optimization of carbon efficiency of production process, the existing studies all try to optimize the logistics distribution. None of them attempt to optimize both production and logistics distribution parameters, and low carbon emission indices. Therefore, this paper explores the multi-objective optimization and carbon efficiency evaluation of flexible production logistics under low carbon constraint. Section 2 determines the constraint order between production logistics time, logistics quality, logistics cost, and low-carbon degree, describes the multi-objective optimization process of the model, and gives the expressions of four linear programming models. Section 3 redefines the carbon efficiency optimization of flexible production logistics, analyses the influence of flexible job-shop production tasks on internal constraint, and builds a mathematical model for the carbon efficiency optimization problem, which simultaneously optimizes carbon emissions and production indices. The proposed model and the modelling idea were proved scientific through experiments.

\section{MULTI-OBJECTIVE OPTIMIZATION OF FLEXIBLE LOGISTICS TIME, QUALITY, COST, AND LOW-CARBON DEGREE}

Under low carbon constraint, the core problem of multi-objective optimization for flexible production logistics is the trade off in the field of production logistics. Before building a multiobjective optimization model, it is necessary to determine the constraint order between production logistics time, logistics quality, logistics cost, and low-carbon degree, and illustrate the process of multi-objective optimization.

The earliest start time $P^{\prime}{ }_{M}$ of the production logistics is set to 0 . Let $Z P$ and $R P$ be the execution time of normal logistics operation and urgent logistics operation, respectively. When urgent operation is permitted, the execution time of each logistics operation satisfies $R P \leq P_{M} \leq Z P$. Let $P_{M}$ be the duration of each logistics operation; $P_{M}^{\prime}$ be the earliest start time of each logistics operation. The execution time of each logistics operation is constrained by $P_{M-1}^{\prime}+P_{M} \leq P^{\prime}{ }_{M}$.

The total logistics time $E P$ of the production cycle is the sum of the execution times of all logistics operations. The objective function of time-oriented linear programming model can be expressed as:

$$
E P=P_{1}+P_{2}+P_{3}+\ldots+P_{M}
$$

Let $E W$ be the execution quality of flexible production logistics operation; $M$ be the number of logistics operations; $A W(M)$ be the slope of the execution quality curve of logistics operations; $I W(M)$ be the intercept of the execution quality curve of logistics operations. Then, the objective function of quality-oriented linear programming model can be expressed as:

$$
E W=\frac{1}{M} \times \sum_{i, j}\left[A W(M) \times P_{M}+I W(M)\right]
$$


As shown in Eq. (2), the quality-oriented linear programming model aims to optimize the mean execution quality of logistics operations. Let $Z W$ and $R W$ be the execution qualities of normal flexible logistics operation and urgent logistics operation, respectively. Then, we have:

$$
\begin{aligned}
& A W(M)=\frac{Z W(M)-R W(M)}{Z P(M)-R P(M)} \\
& I W(M)=R W(M)-A W(M) \times R P(M)
\end{aligned}
$$

Let $A D(M)$ be the slope of the execution cost curve of flexible logistics operations. Then, the objective function of cost-oriented linear programming model can be expressed as:

$$
E D=\sum_{i, j}\left[A D(M) \times P_{M}+I W(M)\right]
$$

As shown in Eq. (4), the cost-oriented linear programming model aims to optimize the cost of logistics operations. Let $Z D$ and $R D$ be the execution costs of normal flexible logistics operation and urgent logistics operation, respectively; $I D(M)$ be the intercept of execution cost curve of logistics operations. Then, $A D(M)$ can be expressed as:

$$
A D(n)=\frac{Z D(M)-R D(M)}{Z P(M)-R P(M)} ; I D(M)=R D(M)-A D(M) \times R P(M)
$$

Let $E H$ be the low-carbon degree of flexible logistics. Then, the low-carbon degree-oriented linear programming model can be expressed as:

$$
E H=\sum_{i, j}\left[A H(M) \times P_{M}+I H(M)\right]
$$

As shown in Eq. (6), the low-carbon degree-oriented linear programming model aims to optimize the low-carbon degree of logistics.

Normally, the lower and upper bounds of logistics goals are configured during the actual operation of production logistics. In this paper, an upper bound $P^{\prime}$ is set for the completion time of logistics operations; a lower bound $W$ is set for the execution quality of logistics operations; an upper bound $D^{\prime}$ is set for the logistics cost; a lower bound $H^{\prime}$ is set for the low-carbon degree. Next, the four linear programming models are detailed as follows.

Under the constraints of execution quality $E W$, logistics cost $E D$, and low-carbon degree $E H$, the optimization model of the completion time of logistics operation can be established as:

$$
\begin{aligned}
& \text { MinEP }=P_{1}+P_{2}+P_{3}+\ldots+P_{M} \\
& \text { S.T. }\left\{\begin{array}{l}
E D \leq D^{\prime} \\
E W \geq W^{\prime} \\
E H \geq H^{\prime}
\end{array}\right.
\end{aligned}
$$

Under the constraints of execution quality $E W$, logistics cost $E D$, and low-carbon degree $E H$, the optimization model of the quality of logistics operation can be established as:

$$
\begin{aligned}
& \operatorname{Max} E P=1 / M \times \sum_{i, j}\left[A W(M) \times P_{M}+I W(M)\right] \\
& \text { S.T. }\left\{\begin{array}{l}
E P \leq P^{\prime} \\
E D \leq D^{\prime} \\
E H \geq H^{\prime}
\end{array}\right.
\end{aligned}
$$

Under the constraints of execution quality $E W$, logistics cost $E D$, and low-carbon degree $E H$, the optimization model of logistics cost can be established as: 


$$
\begin{aligned}
& \operatorname{Min} E D=\sum_{i, j}\left[A D(M) \times P_{M}+I W(M)\right] \\
& \text { S.T. }\left\{\begin{array}{l}
E P \leq P^{\prime} \\
E W \geq W^{\prime} \\
E H \leq H^{\prime}
\end{array}\right.
\end{aligned}
$$

Let $A H(M)$ and $I H(M)$ be the slope and intercept of the low-carbon degree curve for the execution of logistics operations, respectively. Under the constraints of execution quality $E W$, logistics cost $E D$, and low-carbon degree $E H$, the optimization model of low-carbon degree can be established as:

$$
\begin{aligned}
& \operatorname{Max} E D=\sum_{i, j}\left[A H(M) \times P_{M}+I H(M)\right] \\
& \text { S.T. }\left\{\begin{array}{l}
E P \leq P^{\prime} \\
E W \geq W^{\prime} \\
E D \leq D^{\prime}
\end{array}\right.
\end{aligned}
$$

All the above analyses satisfy $Z P \geq R P \geq 0, Z W \geq R W \geq 0, Z D \geq R D \geq 0$, and $Z H \geq R H \geq 0$.

\section{MULTI-OBJECTIVE OPTIMIZATION OF FLEXIBLE LOGISTICS FOR OPTIMAL CARBON EFFICIENCY}

Excessive carbon emissions mean that manufacturers will be charged high taxes. To slash energy consumption of production, and reduce carbon emissions of producers, the carbon efficiency in the production process must be optimized by production enterprises. Compared with the adoption of efficient production equipment, it is easier and less costly to optimize carbon efficiency by adopting advanced materials distribution schemes, implement a scientific framework of production energy.

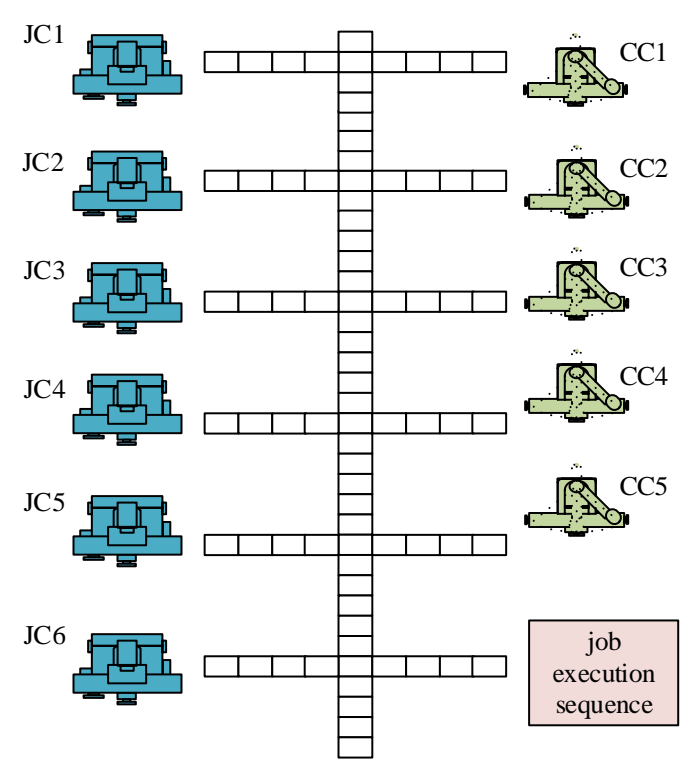

Figure 1: Flexible logistics distribution paths.

This paper re-defines the carbon efficiency optimization of flexible production logistics, analyses how the features of flexible job-shop production tasks influence internal constraints, and develops a mathematical model for the carbon efficiency optimization problem, which simultaneously optimizes carbon emissions and production indices. On this basis, a multi- 
objective weighted optimization algorithm was designed, and the model was solved quickly through normalization and weighting.

During the enterprise production, the carbon footprint is mainly formed by the consumption of production resources, production energy, tools, cutting fluids, and lubricants. Taking turning as an example, this paper discusses the optimization of carbon efficiency. Fig. 1 illustrates the flexible logistics distribution paths.

During the turning process, all processing logistics operations are carried out based on the decisions of job execution sequence and machine allocation. Figs. 2 and 3 show the codes of the two decisions, respectively. In this paper, a binary variable is defined to describe the decisions of job execution sequence and machine allocation:

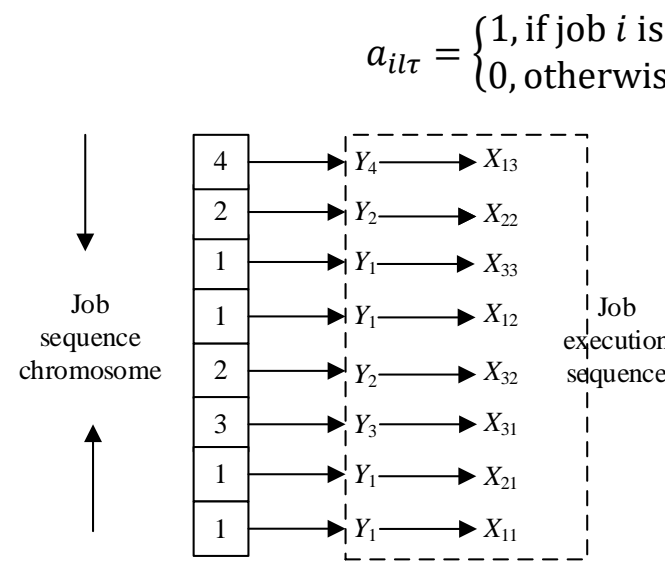

Figure 2: Codes of job sequence decision.

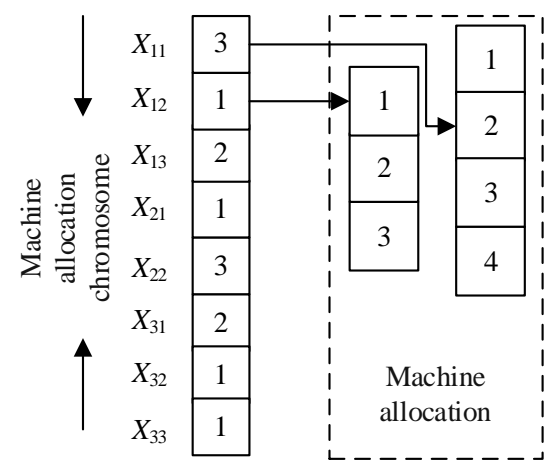

Figure 3: Codes of machine allocation decision.

Let $i \in\{l, 2, \ldots, M\}$ be the serial number of jobs; $I$ be the set of jobs; $M$ be the total number of jobs; $j \in\{l, 2, \ldots, T\}$ be the serial number of logistics operation phases; $J$ be the set of logistics operation phases; $T$ be the total number of logistics operation phases; $l \in\{1,2, \ldots, n\}$ be the serial number of machines; $L$ be the set of machines; $n$ be the total number of machines; $N_{j}$ be the machine faced with a production task in phase $j ; N$ be the total number of machines faced with a production task in phase $j ; L_{j}$ be the set of machines faced with a production task in phase $j$. Then, we have:

$$
l_{j} \in\left\{\sum_{j^{\prime}<j} N_{j^{\prime}}+1, \sum_{j^{\prime}<j} N_{j^{\prime}}+2, \ldots \sum_{j^{\prime}<j} N_{j^{\prime}}\right\}
$$

According to the definition of carbon efficiency optimization for flexible production logistics, the main optimization goals include shortening production logistics time, improving logistics quality, reducing logistics cost, and increasing low-carbon degree. To properly simplify the mathematical model for carbon efficiency optimization, the optimization objectives were simplified as two aspects, namely, logistics operation time, and production 
carbon efficiency, in the light of the actual requirements of turning. The relevant indices can be expressed as follows:

(1) Shortest makespan

The shortest makespan refers to the logistics time needed to complete the last operation of product processing. The makespan means the logistics time consumed by the last completed job. Let $J S_{l \tau}$ be the completion time of machine $l$ at station $\tau$. The shortest makespan can be calculated by:

$$
Q S_{\max }=\min G_{1}=\min \max _{\forall l \in L_{w}, \tau}\left(J S_{l \tau} \times \sum_{i} a_{i l \tau}\right)
$$

(2) Minimum total carbon emissions

The minimum total carbon emissions stand for the lowest carbon emissions of all operations in the production cycle, including processing and logistics. Let $N U^{F}{ }_{l}, N U^{H}$, and $G O^{0}{ }_{l}$ be the noload start energy consumption, no-load stop energy consumption, and no-load power of machine $l$ during processing and logistics operations, respectively; $\varepsilon^{N}{ }_{l}$ be the extra load energy consumption coefficient during turning; $\delta_{i l}$ be the correlation coefficient of turning force; $U_{i l}$ be the volume to be turned, pre-turning diameter, and feed rate of job $i$ on machine $l$, respectively; $B C_{i l}$ be the back cutting depth of machine $l ; r_{i l}{ }^{d}$ be the main shaft speed of machine $l ; \varphi_{1 i l}$ be the back cutting depth coefficient of the tool; $n^{\tau}{ }_{i l}$ be the quality of the tool; $D^{\tau}{ }_{i l}$ be the number of turnings allowed for the tool; $\varphi_{2 i l}$ be the feed rate coefficient of the tool; $\varphi_{3 i l}$ be the main shaft speed coefficient of the tool; $L_{i l}^{\tau}$ be the durability coefficient of the tool. Then, the minimum total carbon emissions can be calculated by:

$$
\begin{gathered}
P C E=\min _{2} \\
\sum_{l \in L_{i}}\left\{\sigma \left[N U_{l}^{F}+\frac{60 U_{i l}^{2} G O_{l}^{0}}{\pi B C_{i l} g_{i l} s_{i l}^{0} r_{i l}^{d}}+\left(1+\varepsilon_{l}^{N}\right) \delta_{i l} g_{i l}^{-0.25} U_{i l} \cdot 10^{-3}\right.\right. \\
\left.\left.=\min \sum_{j} \sum_{i}+N U_{l}^{H}+\frac{60^{1-\varphi_{i l l}}\left(0.4 n_{i l}^{\tau}+1.5\right) U_{i l}^{2} 10^{6}}{L_{i l}^{\tau} D_{i l}^{\tau}\left(\pi s_{i l}^{0} r_{i l}^{d}\right)^{1-\varphi_{1}} B C_{i l}^{1-\varphi_{i l}} g_{i l}^{1-\varphi_{i l l}}}+\frac{60 U_{i l}^{2} U^{g} \lambda^{g} o^{g}}{P^{g} \pi B C_{i l} g_{i l} s_{i l}^{0} r_{i l}^{d}}\right] \times \sum_{\tau} a_{i l \tau}\right\}
\end{gathered}
$$

(3) Minimum of maximum machine load

During the carbon efficiency optimization of flexible production logistics, multiple machines may be available for a logistics operation of a job. Thus, the machine load varies with logistics decisions. To increase logistics operation efficiency and machine utilization rate, the total load of machines in relevant logistics operations should be minimized. Let $M L$ be the maximum machine load during logistics operations; $B E_{l \tau}$ be the start time of no-load state of job $i$ being turned on machine $l$. Then, the minimum of maximum machine load can be calculated by:

$$
M L=\min G_{3}=\min \max _{\forall l}\left\{\sum_{k}\left[\left(J S_{l \tau}-B E_{l \tau}\right) \times \sum_{i} a_{i l \tau}\right]\right\}
$$

To sum up, the objective function of carbon efficiency optimization in flexible production logistics can be written as $\min C E O=\left\{G_{1}, G_{2}, G_{3}\right\}$ in the form of multi-objective optimization.

During the carbon efficiency optimization in flexible production logistics, it is necessary to deliver the materials needed for machines timely, minimize the no-load and stop time of machines, and meet the various process requirements of machines. The following is a detailed description of the various constraints of the turning process.

Let $\Phi^{N}{ }_{l}$ and $G O^{k}{ }_{i l}$ be the maximum utilization rate and maximum rated power of machine $l$, respectively. In the allowable range of processing parameters, the maximum power and maximum turning force should satisfy: 


$$
G O_{i l}^{0}+\frac{\left(1+\varepsilon_{l}^{N}\right) D_{i l}^{G} B C_{i l} g_{i l}^{0.75} n_{i l}^{d} L_{i l}^{G}}{1000 \Phi_{l}} \leq G O_{l}^{\max }
$$

Let $C A^{\max }{ }_{i l}$ be the maximum allowable turning force of machine $l$. During the processing, the cutting force of a machine cannot surpass the maximum allowable turning force:

$$
\frac{D_{i l}^{G} B C_{i l} g_{i l}^{0.75} n_{i l}^{d} L_{i l}^{G}}{60 \times 10^{3}} \leq C A_{i l}^{\max }
$$

The carbon efficiency optimization of flexible production logistics should also satisfy the sequence constraint that a machine must only be turned on at the arrival of materials, following the job sequence decision. During production logistics, a machine can only execute an operation of a job:

$$
\sum_{\tau} \sum_{l \in L_{j}} a_{i l \tau}=1, \forall i, j
$$

During production logistics, a machine can only execute a specific operation of a job:

$$
\sum_{i=1}^{M} a_{i, l, \tau} \leq 1, \forall j, l \in L_{j}, \tau
$$

During production logistics, the logistics sequence of a machine depends on job sequence decision and machine allocation decision:

$$
\sum_{i=1}^{M} a_{i, l, \tau} \geq \sum_{i^{\prime}=1}^{M} a_{i^{\prime}, l, \tau+1}, \forall l, \tau<M
$$

Of course, there are time correlations between logistics operations during production logistics. The relevant constraints are given in Eqs. (21) to (23). The end time of a logistics operation is the sum between the start time of the operation and the processing time of the relevant jobs. Let $\psi^{F}{ }_{i l}$ be the no-load start time of job $i$ being turned on machine $l ; \psi^{H}{ }_{i l}$ be the no-load stop time; $\psi^{k}{ }_{i l}$ and $\psi^{v}{ }_{i l}$ be the loading time and unloading time of job $i$ on machine $l$, respectively. Then, we have:

$$
J S_{l \tau}=B E_{l \tau}+\sum_{i}\left[\left(\psi_{i l}^{k}+\psi_{i l}^{F} \frac{60 U_{i l}}{\pi B C_{i l} g_{i l} s_{i l}^{0} r_{i l}^{d}}+\psi_{i l}^{H}+\psi_{i l}^{v}\right) \times a_{i l \tau}\right], \forall j, l, \tau
$$

The total start time of a logistics operation on a machine must be greater than the completion time of the corresponding operation, and the logistics time of the job in the previous and current operations. Let $\psi^{P} l l^{\prime}$ be the logistics time of a job from machine $l$ to $l^{\prime}$. Then, we have:

$$
B E_{l^{\prime} \tau^{\prime}} \geq \sum_{i}\left[\left(J S_{l \tau}+\psi_{l l^{\prime}}^{P}\right) \times a_{i l \tau} \times a_{i l^{\prime} \tau^{\prime}}\right], \forall j<t, j^{\prime}=j+1, l^{\prime} \in L_{j}, \tau, \tau^{\prime}
$$

On a machine, the previous operation must end earlier than the start of the current operation:

$$
J S_{l \tau} \leq B E_{l, \tau^{\prime}} \quad \forall l, \tau<\tau^{\prime}
$$

\section{EXPERIMENTS AND RESULTS ANALYSIS}

The processing logistics operations are carried out based on job sequence decision and machine allocation decision. Table I shows the complete data on flexible production logistics of different operations, including the operation time of different logistics operations (e.g., normal and urgent operation time), logistics operation quality, logistics operation cost, and low-carbon degree of logistics operation.

This paper constructs a small-scale production case for experiments. Table II lists the relevant parameters of the jobs corresponding to four types of turning operations. Note that $s_{i l}{ }^{1}$ and $s_{i l}{ }^{2}$ are job diameters after rough turning and finish turning, respectively. The loading and unloading time of materials or jobs on machines were obtained through surveys. Table III lists the relevant parameters of the tools. 
Table I: Complete data on flexible production logistics of different operations.

\begin{tabular}{|c|c|c|c|c|c|c|}
\hline Oarameters & 1 & 2 & 3 & 4 & 5 & Total \\
\hline$Z P$ & 3 & 1 & 25 & 26 & 5 & 60 \\
$R P$ & 3 & 2 & 13 & 17 & 6 & 41 \\
$Z W$ & 2 & 1 & 1 & 3 & 2 & 9 \\
$R W$ & 0.5 & 0.9 & 0.7 & 0.6 & 0.4 & 3.1 \\
$Z D$ & 1247 & 1468 & 10574 & 3062 & 1502 & 17853 \\
$R D$ & 1624 & 1825 & 12532 & 3526 & 1824 & 21331 \\
$Z H$ & 625 & 548 & 1725 & 631 & 162 & 3691 \\
$R H$ & 815 & 731 & 2851 & 652 & 230 & 5279 \\
\hline
\end{tabular}

Table II: Job parameters.

\begin{tabular}{|c|c|c|c|c|}
\hline Job & 1 & 2 & 3 & 4 \\
\hline$s_{i l}^{0}(\mathrm{~mm})$ & 32 & 42 & 25 & 82 \\
$s_{i l}{ }^{1}(\mathrm{~mm})$ & 30.5 & 42 & 65.3 & 83.5 \\
$s_{i l^{2}}(\mathrm{~mm})$ & 31 & 42 & 66 & 82 \\
$\delta_{i l}$ & 1524.3 & 1625.8 & 1514.3 & 1526.4 \\
$\psi^{k}{ }_{i l}(\mathrm{~min})$ & 0.56 & 0.75 & 0.95 & 1.25 \\
$\psi^{v}{ }_{i l}(\mathrm{~min})$ & 0.45 & 0.47 & 0.74 & 0.78 \\
\hline
\end{tabular}

Table III: Tool parameters.

\begin{tabular}{|l|c|c|c|c|}
\hline Tool & 1 & 2 & 3 & 4 \\
\hline$n^{\tau}{ }_{i l}(g)$ & 5.2 & 5.3 & 5.2 & 5.3 \\
$L_{i l}^{\tau_{i l}}$ & $4.25 \times 10^{5}$ & $5.27 \times 10^{4}$ & $4.28 \times 10^{5}$ & $4.73 \times 10^{6}$ \\
$D^{\tau}{ }_{i l}$ & 6 & 5 & 4 & 5 \\
$B C_{i l}$ & 0.76 & 0.74 & 0.74 & 0.78 \\
$g$ & 2.23 & 2.24 & 2.26 & 2.25 \\
\hline
\end{tabular}

According to the small-scale production case, the maximum number of logistic operations was set to 2, in view of the logistics distributions required for each machine in the same period. Table IV presents the experimental results under the single objective of $G_{1}, G_{2}$ and $G_{3}$, respectively.

Table IV: Results of the minimization of single objectives.

\begin{tabular}{|c|c|c|c|}
\hline Objective & $\begin{array}{c}\text { Shortest } \\
\text { makespan }\end{array}$ & $\begin{array}{c}\text { Minimum total carbon } \\
\text { emissions }\end{array}$ & $\begin{array}{c}\text { Minimum of maximum } \\
\text { machine load }\end{array}$ \\
\hline$G_{1}$ & 552.162 & 0.235 & 315.26 \\
$G_{2}$ & 451.26 & 0.214 & 385.14 \\
$G_{3}$ & 482.15 & 0.152 & 285.46 \\
\hline
\end{tabular}

As shown in Table IV, the overall optimization effect is often unsatisfactory, if the optimization only targets a single objective. To compare the three objectives with different weights, an improved orthogonal experiment was carried out to weight each single objective. Let $\omega_{1}, \omega_{2}$, and $\omega_{3}$ be the weights of $G_{1}, G_{2}$, and $G_{3}$, respectively. Figs. 4 and 5 present the principal component analysis (PCA) results of weights $\omega_{1}$ and $\omega_{2}$, respectively. 


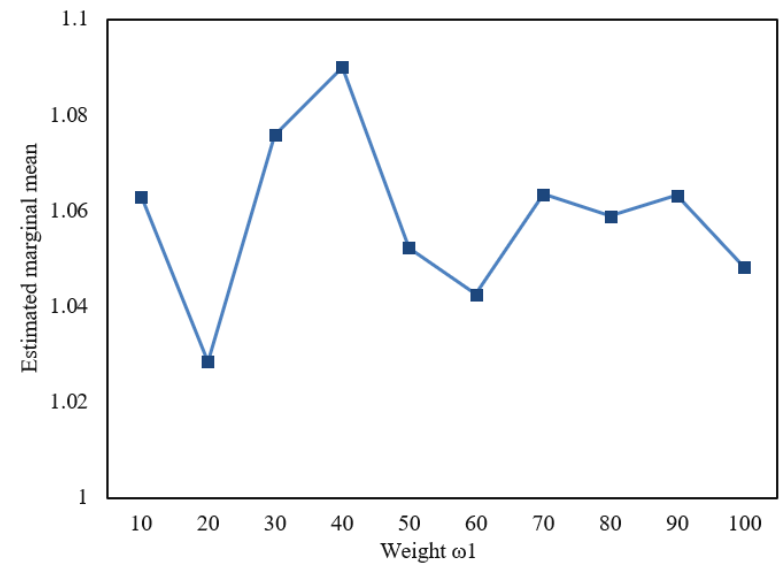

Figure 4: PCA results of weight $\omega_{1}$.

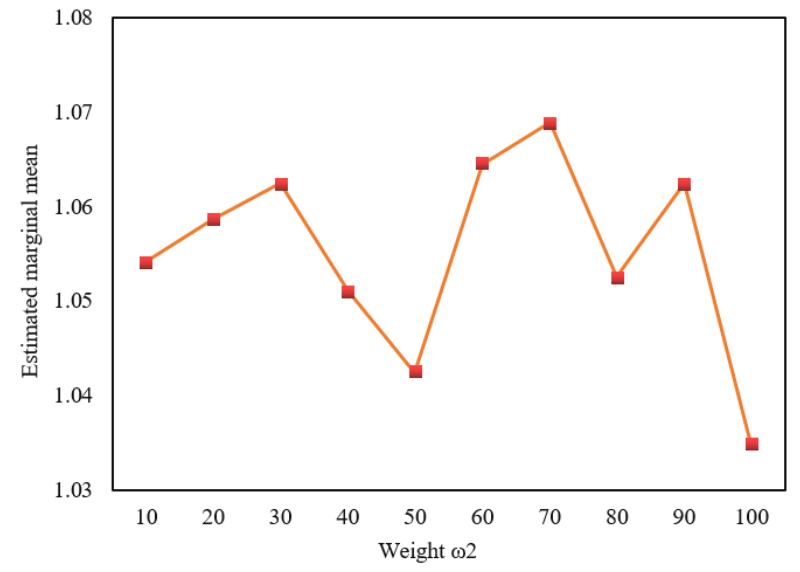

Figure 5: PCA results of weight $\omega_{2}$.

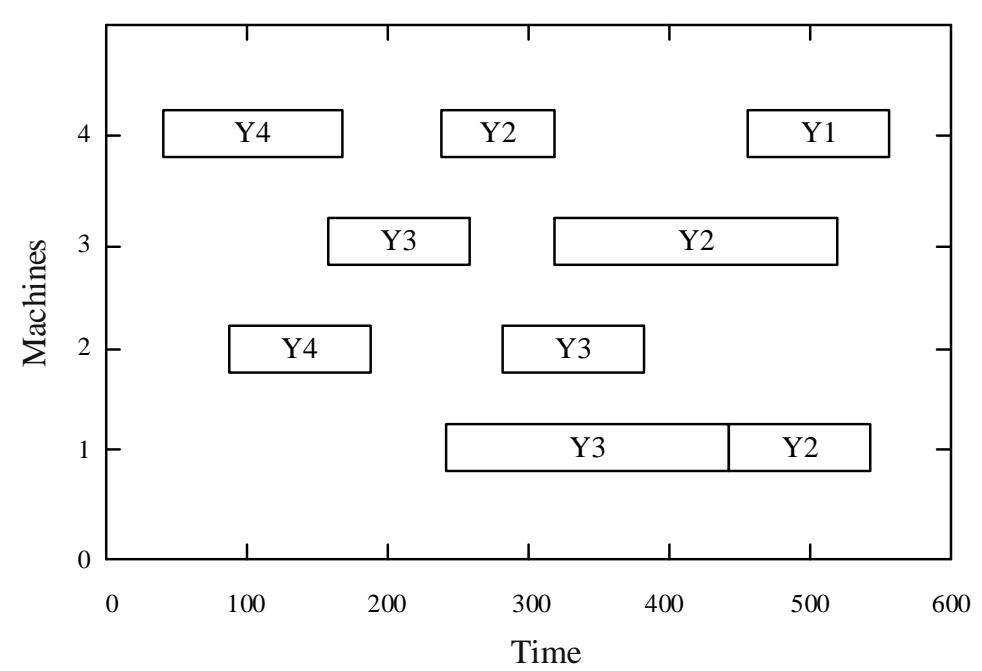

Figure 6: Gantt chart of the logistics distribution scheme corresponding to the optimal results of a single objective.

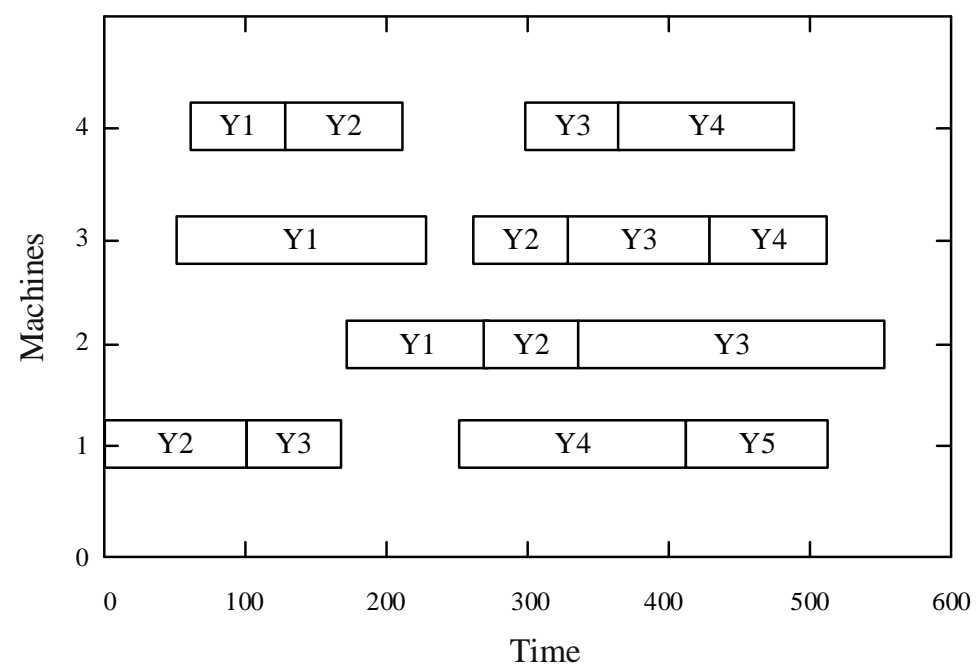

Figure 7: Gantt chart of the logistics distribution scheme corresponding to the optimal results of the composite objective.

Through single-factor multivariate analysis of variance (MANOVA), the optimal weight combination can be obtained as $\omega_{1}=0.65, \omega_{2}=0.15$, and $\omega_{3}=0.2$. The weight combination was imported to the objective model for carbon efficiency optimization of flexible production 
logistics, trying to minimize the composite objective. The results show $C E O=1.1157$, $Q S_{\max }=457.62 \mathrm{~s}, P C E=0.164 \mathrm{~kg}$, and $M L=255.87 \mathrm{~s}$. Figs. 6 and 7 present the Gantt charts of the logistics distribution schemes corresponding to the optimal results of a single objective and the composite objective, respectively.

As shown in Figs. 6 and 7, the makespan increased mainly because machines 1 and 3, which are relatively efficient, received more logistics tasks. This effectively lowered the total carbon emissions and maximum machine load, such that the composite optimization objective dropped from 1.1157 to 1.0641 . Therefore, weighted objective optimization can simultaneously optimize the three single objectives of makespan, total carbon emissions, and maximum machine load.

During the production, different objective values of carbon efficiency optimization for flexible production logistics can be obtained under different constraints of logistics operation time, logistics operation quality, and logistics operation cost. The specific values are recorded in Table V. Combined with the specific objective functions and constraints mentioned previously, a multi-objective optimization model can be established to truthfully reflect the actual production process.

Table V: Optimal low-carbon degrees.

\begin{tabular}{|c|c|ccccc|ccccc|}
\hline $\begin{array}{c}\text { Logistics operation } \\
\text { time }\end{array}$ & \multicolumn{5}{|c|}{37.1} & \multicolumn{5}{c|}{48.9} \\
\hline $\begin{array}{c}\text { Logistics operation } \\
\text { quality }\end{array}$ & 18263 & 19205 & 19825 & 20315 & 21513 & 17524 & 18634 & 19374 & 20215 & 21605 \\
\hline $\begin{array}{c}\text { Logistics operation } \\
\text { cost }\end{array}$ & 145.2 & 155.6 & 149.5 & 134.8 & 144.8 & 137.4 & 122.8 & 185.4 & 174.5 & 177.4 \\
\hline & 0.7 & 4812.34 & 4125.32 & 3829.26 & 3853.12 & 3741.16 & 3926.15 & 4215.40 & 4516.38 & 4628.47 & 4926.15 \\
Low-carbon & 0.75 & 4516.29 & 4826.37 & 4725.16 & 4927.12 & 4562.37 & 4826.59 & 4735.26 & 4825.16 & 4928.35 & 4726.32 \\
degree & 0.81 & 4726.59 & 4125.10 & 4426.32 & 4925.81 & 5136.26 & 4926.34 & 5021.26 & 4826.57 & 4926.38 & 4472.51 \\
& 0.87 & $/$ & $/$ & 4526.35 & 4812.25 & 451.29 & $/$ & $/$ & $/$ & 4125.36 & 4825.16 \\
& 0.96 & $/$ & $/$ & $/$ & 4825.96 & 4725.36 & 4516.29 & $/$ & $/$ & $/$ & 4826.35 \\
\hline
\end{tabular}

\section{CONCLUSIONS}

This paper thoroughly examines the multi-objective optimization and carbon efficiency evaluation of flexible production logistics under low carbon constraint. After defining the constraint order between production logistics time, logistics quality, logistics cost, and lowcarbon degree, the authors provided the expressions of four linear programming models. Next, the carbon efficiency optimization of flexible production logistics was redefined, and a mathematical model was developed for the carbon efficiency optimization problem, which simultaneously optimizes carbon emissions and production indices. Thence, a small-scale production case was constructed for experiments, and the results of each single objective $G_{1}$, $G_{2}$ and $G_{3}$ were obtained. To compare the three objectives with different weights, an improved orthogonal experiment was carried out to weight each single objective. On this basis, the authors obtained the PCA results on weights $\omega_{1}$ and $\omega_{2}$, as well as the Gantt charts of the logistics distribution schemes corresponding to the optimal results of a single objective and the composite objective, respectively. The experimental results show that weighted objective optimization can simultaneously optimize the three single objectives of makespan, total carbon emissions, and maximum machine load. In addition, different objective values of carbon efficiency optimization for flexible production logistics were obtained under different constraints. 


\section{ACKNOWLEDGEMENT}

We'd like to thank Management Modernization Research Center of Inner Mongolia for helping and supporting the writing of this manuscript.

\section{REFERENCES}

[1] Koblasa, F.; Kralikova, R.; Votrubec, R. (2020). Influence of EA control parameters to optimization process of FJSSP problem, International Journal of Simulation Modelling, Vol. 19, No. 3, 387-398, doi:10.2507/IJSIMM19-3-519

[2] Zhao, C.; Kang, N.; Li, J.; Horst, J. A. (2017). Production control to reduce starvation in a partially flexible production-inventory system, IEEE Transactions on Automatic Control, Vol. 63, No. 2, 477-491, doi:10.1109/TAC.2017.2717940

[3] Ojstersek, R.; Acko, B.; Buchmeister, B. (2020). Simulation study of a flexible manufacturing system regarding sustainability, International Journal of Simulation Modelling, Vol. 19, No. 1, 6576, doi:10.2507/IJSIMM19-1-502

[4] Radygin, A. B.; Sergeev, A. I.; Serdyuk, A. I. (2019). Flexible production systems with probabilistic perturbations, Russian Engineering Research, Vol. 39, No. 1, 60-65, doi:10.3103/ $\underline{\text { S1068798X19010088 }}$

[5] Lyu, G.; Cheung, W.-C.; Chou, M. C.; Teo, C.-P.; Zheng, Z.; Zhong, Y. (2019). Capacity allocation in flexible production networks: theory and applications, Management Science, Vol. 65, No. 11, 5091-5109, doi: $10.1287 / \mathrm{mnsc} .2018 .3169$

[6] Zhao, L.; Chen, C. (2019). Static scheduling problem of flexible production workshop based on multi-factor scheduling model, Academic Journal of Manufacturing Engineering, Vol. 17, No. 4, 176-181

[7] Naim, M.; Aryee, G.; Potter, A. (2010). Determining a logistics provider's flexibility capability, International Journal of Production Economics, Vol. 127, No. 1, 39-45, doi:10.1016/ j.ijpe.2010.04.011

[8] Wang, X.; Wang, L. (2018). Green routing optimization for logistics distribution with path flexibility and service time window, Proceedings of $201815^{\text {th }}$ International Conference on Service Systems and Service Management (ICSSSM), 5 pages, doi:10.1109/ICSSSM.2018.8464993

[9] Jafari, H.; Nyberg, A.; Hilletofth, P. (2016). Postponement and logistics flexibility in retailing: a multiple case study from Sweden, Industrial Management \& Data Systems, Vol. 116, No. 3, 445465, doi:10.1108/IMDS-06-2015-0257

[10] Ngamsirijit, W. (2013). Using capacity flexibility model for responsive tourism logistics: the case of Pattaya city, Proceedings of 2013 IEEE International Conference on Service Operations and Logistics, and Informatics, 404-407, doi:10.1109/SOLI.2013.6611448

[11] Bai, C.; Sarkis, J. (2013). Flexibility in reverse logistics: a framework and evaluation approach, Journal of Cleaner Production, Vol. 47, 306-318, doi:10.1016/j.jclepro.2013.01.005

[12] Liu, M.; Li, G.; Yao, Q. (2012). Flexibility value of node enterprise's logistics capability in decentralized supply chain, Journal of Convergence Information Technology, Vol. 7, No. 15, 270278

[13] Lieberoth-Leden, C.; Fischer, J.; Fottner, J.; Vogel-Heuser, B. (2018). Control architecture and transport coordination for autonomous logistics modules in flexible automated material flow systems, Proceedings of 2018 IEEE $14^{\text {th }}$ International Conference on Automation Science and Engineering (CASE), 736-743, doi:10.1109/COASE.2018.8560471

[14] Xue, G. (2017). Research of large parts of the NC flexible logistics unit, Proceedings of $20178^{\text {th }}$ International Conference on Mechanical and Intelligent Manufacturing Technologies (ICMIMT), 93-96, doi:10.1109/ICMIMT.2017.7917442

[15] Dai, Y.; Gao, H. O. (2016). Energy consumption in China's logistics industry: a decomposition analysis using the LMDI approach, Transportation Research Part D: Transport and Environment, Vol. 46, 69-80, doi:10.1016/j.trd.2016.03.003

[16] Ojstersek, R.; Lalic, D.; Buchmeister, B. (2019). A new method for mathematical and simulation modelling interactivity: a case study in flexible job shop scheduling, Advances in Production Engineering \& Management, Vol. 14, No. 4, 435-448, doi:10.14743/apem2019.4.339 
[17] Harris, T. M.; Devkota, J. P.; Khanna, V.; Eranki, P. L.; Landis, A. E. (2018). Logistic growth curve modeling of US energy production and consumption, Renewable and Sustainable Energy Reviews, Vol. 96, 46-57, doi:10.1016/j.rser.2018.07.049

[18] Yang, B.; Guo, Y. Y.; Shi, X.; Lu, Y. Y. (2012). Research on the energy consumption evaluation model of container terminal logistics system, Applied Mechanics and Materials, Vols. 157-158, 1224-1229, doi:10.4028/www.scientific.net/AMM.157-158.1224

[19] Zając, P. (2011). The idea of the model of evaluation of logistics warehouse systems with taking their energy consumption under consideration, Archives of Civil and Mechanical Engineering, Vol. 11, No. 2, 479-492, doi:10.1016/S1644-9665(12)60157-5

[20] Cai, J.; Liu, R.; Xiong, J.; Cui, Q. (2016). A new five-parameter logistic model for describing the evolution of energy consumption, Energy Sources, Part B: Economics, Planning, and Policy, Vol. 11, No. 2, 176-181, doi:10.1080/15567249.2011.592902

[21] Lin, T. T.; Chan, M.-T. (2011). A decision analysis on flexible scale of green logistics under limited carbon emission with real options concept, Proceedings of 2011 IEEE International Conference on Industrial Engineering and Engineering Management, 11-15, doi:10.1109/ IEEM.2011.6117869

[22] Ying, Z. (2021). Low carbon logistics network planning based on green supply chain, Proceedings of $202113^{\text {th }}$ International Conference on Measuring Technology and Mechatronics Automation (ICMTMA), 86-89, doi:10.1109/ICMTMA52658.2021.00029

[23] Islam, M. A.; Gajpal, Y.; ElMekkawy, T. Y. (2021). Mixed fleet based green clustered logistics problem under carbon emission cap, Sustainable Cities and Society, Vol. 72, Paper 103074, 14 pages, doi:10.1016/j.scs.2021.103074

[24] De, M.; Das, B.; Maiti, M. (2018). Green logistics under imperfect production system: a rough age based multi-objective genetic algorithm approach, Computers \& Industrial Engineering, Vol. 119, 100-113, doi:10.1016/j.cie.2018.03.021

[25] Nouira, I.; Frein, Y.; Hadj-Alouane, A. B. (2012). On the modeling of logistic decisions impacts on product greenness: sensitivity analysis, Daniel, F.; Barkaoui, K.; Dustdar, S. (Eds.), International Conference on Business Process Management (BPM 2011), Business Process Management Workshops, Lecture Notes in Business Information Processing, Vol. 100, Springer, Berlin, 162-176, doi: $10.1007 / 978-3-642-28115-0 \quad 16$

[26] Mao, C. L. (2021). Production management of multi-objective flexible job-shop based on improved PSO, International Journal of Simulation Modelling, Vol. 20, No. 2, 422-433, doi:10.2507/ IJSIMM20-2-CO11 